mechanism was to be introduced to curb the consumer. Ideas for the future were to be developed in the pilot private health maintenance practice in Harrow, and in due course plans for a more competitive, attractive, and cost effective service were to be revealed.

Two years later, after detailed studies in the Binder-Hamlyn report, which we have paid for but not been allowed to see, and trips to the USA to look at vastly more expensive systems nowhere accessible to the whole population, we are still waiting. By now even this government must know that Harrow cannot represent common social experience and does not contain the most serious problems of general practice, to be found mainly in inner cities and areas of industrial disinvestment, and even in its own specially favourable circumstances has failed to work profitably. It seems more and more doubtful whether British general practice can be made any cheaper than it already is. The only scope for marketing would be in some kind of two tier service, and responsibility for any move in that socially divisive direction would be electorally disastrous

Just as Mr Clarke must have been wondering whether it might be cheaper and wiser to leave Lloyd George's contract essentially undisturbed for its 74th year, he has been thrown a lifebelt in the form of the Roval College of General Practitioners discussion paper on a quality related contract (29 June, p 1981). Even now it seems possible that no green paper will ever appear; but if it does, its point d'appui will be the RCGP discussion paper. Of course, we do need a new contract: Lloyd George, even as expanded by Bevan and modified by the 1966 package deal, encouraged mediocrity by guaranteeing tenure within an unplanned and unplannable service and restrained investment and innovation in primary care by making us anomalous businessmen, obliged to give service but not allowed to charge for it, encouraging perfunctory rather than comprehen sive care. The advances in quality gained by the substantial increases in public investment of the 1966 package were seen to be exhausted, change was in the air, and it seemed a good time to put forward constructive ideas for a fundamental revision.

I have been a member of the general purposes committee of RCGP council since drafting of the discussion paper began in November 1984 and share responsibility for it. At none of the many committee meetings I attended (I think I missed only two) was a vote taken, and throughout it has been developed as a consensus document. Initially several of us proposed that the paper should include several options so that all could de debated. The first three or four drafts did mention fee for service and salary schemes, both dismissively, but other alternatives put forward publicly by members of the committee during the year (Marshall Marinker's voucher scheme for minicorporate competition, and my own proposals for a contract including responsibility for outreach preventive and anticipatory care of whole registered populations) were not included in any draft. Though, as I recall, no decision was ever taken to abandon the multiple options idea, in fact it was dropped. A camel is a horse designed by a committee, and the final draft, nominally written by chairman Donald Irvine, secretary Bill Styles, and Marshall Marinker, endorsed by the general purposes committee and subsequently by council, certainly is more of a horse than its many predecessors Inevitably, it actively represents the views of its author, modified by what his committees will tolerate, and only passively reflects the agreement, bewilderment, or exhaustion of the rest of us.

The document has now gone out to the membership for discussion, and that is exactly what it needs: critical discussion, not hard sales-as $\operatorname{Dr} P$ D Campion says (24 August, p 499), it deserves careful reading by all general practitioners. Outside Princes Gate it may be easier to see it in its real political context. We are dealing with a government which is dismantling rather than building all public services except the police, and any "quality related contract" we get from it will be at best a dog's dinner, and at worst a system for encourag ing private practice where markets are thought to exist, while putting the screws on the doctors of derelict populations by blaming them for situations they may have capitulated to but certainly have not created.

Naively, I had hoped the college would initiate plans for a primary care service orientated toward need and the population after the present social war, in rather the same way as much of the NHS was planned by the joint planning committee of the BMA during the second world war. Rather than negotiate a new contract in the present dangerous circumstances, we need to concentrate on defending what we have, seeking allies among our patient rather than in the corridors of power. At least, unlike the hospitals, breakdowns in general practice are not yet "solved" by accepting private fee for adequate non-emergency service. For the time being, the best we can achieve within the presen obsolete contract, though not nearly enough, may be all we can do without risking something very much worse.

Glyncorrwg Health Centre,

JULIAN TUdOR HART

West Glamorgan SA13 3BL

SIR,-I was heartened to read Dr P D Campion's leading article. I share his concern about the royal college's consultation document, which makes many assumptions that should be firmly challenged.

I agree with the concept of quality in genenera practice wholeheartedly, but the college is beginning to stray into a political minefield by becoming concerned with contracts, remuneration, and in centives. Contracts and remuneration are a part of general practice which the college would do well to leave to the BMA, which has had many years of experience in negotiating on behalf of doctors. believe that the Royal College of General Practitioners is becoming involved in power broking especially bearing in mind its recent involvemen in discussions with the Health Minister on the limited list, which must have been seen as detracting from the BMA's standpoint. A governmen with a strong majority in the Commons may well take the advantage on future issues to press home its advantage of divide and rule if the college continues to get involved in political problems.

Furthermore, it is inopportune for the college to make this a consultation document, yet agree to discuss the unrevised document with the Health Minister before receiving feedback from its members. Maybe it takes its members for granted.

The consultation document concludes that the five provisions or elements for the strategy for "quality"-namely, the professional development of doctors, practice management and teamwork, quality assessment, contracts and incentives, and resource need-ultimately depend on adequate funding for incentive. It is all very well to demand resources for well intentioned ideals, but who will provide these resources? The present government clearly has other priorities for resources, such as defence.

Whereas the aims of the document are laudable and one should always strive for quality in general practice, the method by which the college hopes to achieve this ideal should be challenged. The college should leave the politics to those more qualified and more experienced.

I.udgershall, Wilts

A D GREIG

\section{Creutzfeldt-Jakob disease}

SIR,-In our article (3 August, p 299) we assert that Creutzfeldt-Jakob disease does not occur in individuals conjugally related to patients with the disease. Professor W B Matthews (17 August, p 483) draws attention to three cases of CreutzfeldtJakob disease which he describes as conjugal. Of these patients, one was the sister in law of the half sister of the mother of two affected sisters, ${ }^{1}$ another was a sister in law of the sister in law of two affected sisters, ${ }^{2}$ and the third was the wife of a cousin of two affected siblings. ${ }^{3}$ The evidence therefore concerns individuals related somewhat indirectly by marriage rather than married to and cohabiting with the affected person. A further point worth raising is whether genetic relatedness (which may occur in relatively small communities) can be excluded. For example, the second case occurred in Chile, where there is known to be an exceptionally high incidence of familial Creutzfeldt-Jakob disease. $^{2}$

There is no independent reason for believing (as Professor Matthews suggests) that familial Creutzfeldt-Jakob disease involves an agent more virulent than that associated with sporadic Creutzfeldt-Jakob disease. As we have shown, both are easily transmitted to primates with similar incubation periods and neuropathology; duration of illness is not shorter in familial CreutzfeldtJakob disease ${ }^{+}$and is considerably longer in familial Gerstmann-Straussler syndrome ${ }^{\varsigma}$ than in sporadic Creutzfeldt-Jakob disease.

Since several authors report that $10-15 \%$ of cases of Creutzfeldt-Jakob disease are familial in a distribution compatible with dominant inheritance, and very large pedigrees showing an autosomal dominant pattern are known ${ }^{346}$ we do not feel compelled to accept Professor Matthews's assertion that "whatever the cause, it is certainly not genetic."

While we agree that the incubation period of kuru can be very long, it was often very short, such that death from kuru could occur at any age and deaths in children and young women were very common. In contrast, epidemiological studies have consistently shown that Creutzfeldt-Jakob disease is essentially a disease with onset in later middle age. ${ }^{2+4}$ Professor Matthews's own study showed that " $80 \%$ of patients died between the ages of 50 and $69 . " 7$ This is what we have referred to as a "circumscribed age of onset," although Professor Matthews rightly draws attention to exceptional cases outside this age range.

Our suggestion is that the solution of the problem of familial transmissible dementia lies not in deciding between "genetic versus infection transmission" but in understanding the way in which an inherited gene or genes can give rise to a transmissible agent.

H F BAKER R M RIDLEY T J CROW

\section{Division of Psychiatry,}

Clinical Research Centre,
Harrow, Middlesex HA1 $3 \mathrm{U}$

1 Will RG, Matthews WB. Evidence for case-to-case transmission of Creutzfeldt-Jakob disease. I Neurol Neurosurg Psychiatry 1982;45:235-8.

2 Galvez S, Cartier L, Monari M, Araya G. Familial CreutzfeldtJakob disease in Chile. 7 Neurol Sci 1983;59:139-47.

3 Brown P, Cathala F, Gajdusek DC. Creutzfeldt-Jakob disease in France: III Epidemiological study of 170 patients dying during France: III Epidemiological study of 170 patients dyin
the decade 1968-1977. Ann Neurol 1979;6:438-46. 
4 Masters CL, Gajdusek DC, Gibbs CJ. The familial occurrence of Creutzfeldt-Jakob disease and Alzheimer's disease. Brain $1981 ; 104: 535-58$

5 Masters CL, Gajdusek DC, Gibbs CJ. Creutzfeldt-Jakob disease virus isolations from the Gerstmann-Straussler Syndrome. Brain 1981:104:559-88.

6 Masters CL, Harris JO, Gajdusek DC, Gibbs CJ, Jr, Bernoulli C, Asher DM. Creutzfeldt-Jakob disease: patterns of worldwide Asher DM. Creutzfeldt-Jakob disease: patterns of worldwide
occurrence and the significance of familial and sporadic

7 Will RG, Matthews W'B. A retrospective study of Creutzfeldt Jakob disease in England and W'ales 1970-79. I. Clinical features. F Neurol Neurosurg Psychiaty 1984;47: 134-40.

\section{Brittle diabetes}

SIR,-The psychiatric aspects of patients with brittle diabetes mellitus have not been studied in detail. ${ }^{1}$ However, I can provide some rare psychiatric data relevant to Dr Robert Tattersall's comments (31 August, p 555).

Three years ago I had the opportunity to study a sample of seven girls and women with brittle diabetes (mean age 21 years) who were under the care of Professor Keen at the unit for metabolic medicine, Guy's Hospital, London. All had long and extensive histories of unstable diabetes with numerous hospital admissions. They were studied by questionnaire and interview in hospital after recovery from an episode of diabetic metabolic decompensation. Plasma glucose concentration was $5-10 \mathrm{mmol} / \mathrm{l}(91-182 \mathrm{mg} / 100 \mathrm{ml})$ at the beginning of the assessment, and a snack was provided halfway through the one to one and a half hour assessment.

The patients completed the state-trait anxiety inventory, ${ }^{2}$ the Eysenck personality questionnaire, ${ }^{3}$ and the eating attitudes test,${ }^{4}$ and were interviewed with the clinical interview schedule 5 a standardised psychiatric interview-and the standardised social interview. ${ }^{6}$

Two patients were aged over 20 years ( 26 and 37 ) and the rest were younger (15-19). The older women scored highly on the state-trait anxiety inventory measure of anxiety trait $($ mean $=77$ ), well above the reference range $($ mean $=45$ ) for general medical and surgical patients with psychiatric complications. On the Eysenck personality questionnaire they were highly introverted (mean extraversion score of 1) and scored as highly as neurotic subiects on the Eysenck personality questionnaire dimension of neuroticism (mean score 19; Eysenck's reference group mean $=18$ ). Both were judged to be psychiatric "cases" on the clinical interview schedule, and both were given psychiatric diagnoses of depression. Moreover, the standardised social interview showed them to have serious social difficulties, especially in personal relationships, and particularly with their sexual partners.

The younger women also scored as highly as neurotic subjects on the Eysenck questionnaire dimension of neuroticism (mean score $=18$ ). Again, all were found to be psychiatric "cases" on the clinical interview schedule, but they did not have well defined psychiatric conditions: most showed a mixture of anxiety, depression, and irritability. Furthermore, this group also had serious social difficulties, mainly few opportunities for leisure and problems with their families because of the disruptive influence of their diabetic condition.

Finally, one patient in each group scored in the range suggestive of anorexia nervosa on the eating attitudes test $(>30)$.

Although these observations were uncontrolled and were not based on a random sample of patients with brittle diabetes, and disregarding the direction of causality, I conclude that psychiatric and social morbidity are probably common in women with a severe form of this disorder. And I support the view that psychiatric assessment and back up are necessary in the joint treatment of these patients. The diabetologist and the general practitioner are best placed to organise and maintain whatever psychiatric and social care is appropriate in the individual patient's case.

GREG WILKINSON

General Practice Research Unit,

Institute of Psychiatry,

London SE5 8AF

1 Wilkinson DG. Psychiatric aspects of diabetes mellitus. $\mathrm{Br} \mathcal{F}$ Psychiatry 1981;138:1-9.

2 Spielberger CD, Gorsuch RL, Lushene RE. Manual for the state-

trait anxiety inventory (self-evaluation questionnaire). Palo Alto, tratt anxiety inventory (self-evaluation questionnaire)

Eysenck HJ, Eysenck SBG. Manual of the Eysenck personality questionnaire (junior and adult). London: Hodder and Stoughton, 1975

4 Garner DM, Garfinkel PE. The eating attitudes test: an index of the symptoms of anorexia nervosa. Psychol Med 1979;9:273-9. Goldberg DP, Cooper B, Eastwood MR, Kedward HB, Shepherd $M$. A standardised psychiatric interview for use in community surveys. Br f Prev Soc Med 1970;24:18-23.

6 Clare AW, Cairns VE. Design, development and use of a standardized interview to assess social maladjustment and dysfunction in community studies. Psychol Med 1978;8: $589-604$.

Raised plasma glutathione S-transferase values in hyperthyroidism and in hypothyroid patients receiving thyroxine replacement

SIR,-The report by Dr G J Beckett and others (17 August, p 427) draws conclusions, based on small numbers of patients, which appear to fly in the face of everyday experience. I have never seen or heard of a patient treated and monitored for hypothyroidism in the usual way subsequently developing liver disease as a result. I wonder if they have? It seems likely that many laboratories will in the near future start to use a sensitive assay of thyroid stimulating hormone as their standard thyroid function test and I question the wisdom of maintaining the troublesome free thyroxine assay to prevent liver dysfunction so subtle that it cannot be detected by conventional means and which appears not to be progressive. Their recommendations are really not justified on the basis of the data they present.

Staffordshire General Infirmary,

Peter Daggett Stafford ST162PA

Drs G J Beckett and A D Toft reply below.$\mathrm{ED}, \boldsymbol{B M \mathcal { H }}$.

SIR,-Although our initial report was based on small numbers we have now extended our studies to over 100 patients receiving thyroxine replacement therapy and find that $20 \%$ have abnormal liver function tests. As before, these abnormalities most commonly occur when serum free thyroxine values are raised. As we showed in our paper, abnormalities in liver function tests are not confined to glutathione $\mathrm{S}$-transferase measurements but were also observed with the more conventional chemical tests of liver function. Like Dr Daggett, we are not aware of patients receiving conventional doses of thyroxine replacement therapy in whom overt liver disease, attributable to their treatment, has developed. On the other hand, we do not know of any study which examines the incidence of abnormal liver histology in patients treated with thyroxine, although the changes in thyrotoxicosis are well documented. The association between raised serum free thyroxine and abnormal liver function tests in some patients receiving replacement therapy suggests that such patients are being overtreated. Rather than disregard a high free thyroxine value in a patient who appears clinically euthyroid it would seem sensible to reduce thyroxine intake to a dose which can provide adequate replacement as judged by normal free thyroxine and thyroid stimulating hormone valves and there fore avoid abnormalities in liver function tests.

Dr Daggett's comments regarding the use of sensitive assays of thyroid stimulating hormone as a standard thyroid function test in patients taking thyroxine are topical. We are advocates of the use of such assays as a first line test in the diagnosis of thyroid disease. Although the diagnostic role of sensitive thyroid stimulating hormone assays is accepted, their place in monitoring the adequacy of thyroxine replacement is still controversial. Our experience indicates that it is necessary to combine measurement of thyroid stimulating hormone with measurement of thyroid hormone values, preferably free thyroxine.

G J BECKETT A D ToFT

Departments of Clinical Chemistry and Medicine,

Roval Infirmary, Edinburgh EH3 9YW

Misleading guidelines on oxygen treatment in asthma

SIR,-The current edition of the British National Formulary states (and previous editions have stated the same): "In severe acute asthma, the arterial plasma $\mathrm{PaCO}_{2}$ is subnormal initially but may later rise steeply (particularly in children) and arterial blood gas studies are essential to determine the concentration of oxygen to be delivered to the patient. Where facilities for blood gas measurements are not immediately available, for example while transferring the patient to hospital, the safest compromise would probably be to administer oxygen in concentrations of $24 \%$ or $28 \%$ with a Ventimask." We believe this statement to be misleading and potentially dangerous.

The $\mathrm{PaCO}_{2}$ can rise during severe acute attacks of asthma, this phenomenon being an indication of the severity of the episode and of the need to consider the use of mechanical ventilation. This rise in $\mathrm{PaCO}_{2}$ is secondary to the fall in alveolar ventilation and is always associated with arterial hypoxaemia. Such patients are at risk of death from hypoxaemia, which is unlikely to be much improved by $24 \%$ or $28 \%$ oxygen.

We are not aware of evidence which suggests that patients with asthma have reduced medullary chemoreceptor sensitivity to carbon dioxide or that they are dependent on "hypoxic drive" to maintain ventilatory effort. There can, therefore, be no contraindication to the use of concentrations of inspired oxygen greater than $28 \%$.

We recommend that all patients with severe acute asthma should be given oxygen in a concentration of at least $35 \%$ during transit to hospital. The recommendations in the British National Formulary are incorrect and dangerous and should be modified as soon as possible.

A T ELDER

Respiratory Unit,

G K CROMPTON

Northern General Hospital

Edinburgh EH5 2DQ

1 Joint Formulary Committee 1985-6. British National Formulary. No 10. London: British Medical Association and Pharmaceutical Society of Great Britain, 1985:3.6, p 123.

\section{Idiopathic hypopituitarism in the elderly}

SIR,-We read with interest the recent short report by Dr P E Belchetz (27 July, p 247). We consider, however, that in the elderly the simple 